\title{
Interactive comment on "The SP19 Chronology for the South Pole Ice Core - Part 1: Volcanic matching and annual-layer counting" by Dominic A. Winski et al.
}

\section{Dominic A. Winski et al.}

dominic.winski@maine.edu

Received and published: 13 August 2019

Thank you very much for the very useful and positive comments. We greatly appreciate your input. Below are our line-by-line responses to your review.

In the paper "The SP19 Chronology for the South Pole Ice Core - Part 1: Volcanic matching and annual-layer counting" by D. A. Winsky and co-authors a new timescale (called SP19) for the SPICEcore is presented. This new time scale was partly achieved by annual layer counting but the main guide to build the age scale is a robust volcanic match coming from a comparison with WAIS Divide ice core chronology. Given the best quality of annual layering in WAIS Divide (as shown in figure 4) I think that the authors 
choose the best methodological approach to build this time scale, considering WAIS as the most reliable annually counted scale. The discussion about the uncertainty of the age scale is really well done and confirms the goodness of this first SP19 age scale both for the Holocene period (with a maximum uncertainty of about 25 years) and for older ice (maximum 124 years in the longest time window without tie points). The paper is clear and well written and I recommend its publication after considering the following minor points.

-Thank you!

Minor comments: Figure 5: I would recommend to change the x-axis in kyr BP instead of using $\times 10 \mathrm{ËE}_{2} 4$. In my opinion it would be much readable.

-We have changed the $x$-axis in Figure 5.

A list (table) of the volcanic horizons used to match WDC and SPICEcore would be valuable if inserted in the text or in supplementary material (even if archived at the NCDC or other repository).

-The timescale and a full list of tie points will be archived in the supplementary material and will be available at the National Climate Data Center (www.ncdc.noaa.gov) and the U.S. Antarctic Program Data Center (http://www.usap-dc.org). This data is also attached here.

Line 427: I would change this sentence to "Below 798 m depth (start of the Holocene): ::."

-Fixed.

Please also note the supplement to this comment:

Printer-friendly version

https://www.clim-past-discuss.net/cp-2019-61/cp-2019-61-AC2-supplement.zip

Discussion paper

Interactive comment on Clim. Past Discuss., https://doi.org/10.5194/cp-2019-61, 2019.

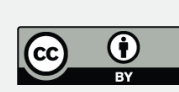

